\title{
Earthquake rupture properties and tsunamigenesis in the shallowest megathrust
}

V. Sallarès, C. R. Ranero, M. Prada, A. Calahorrano

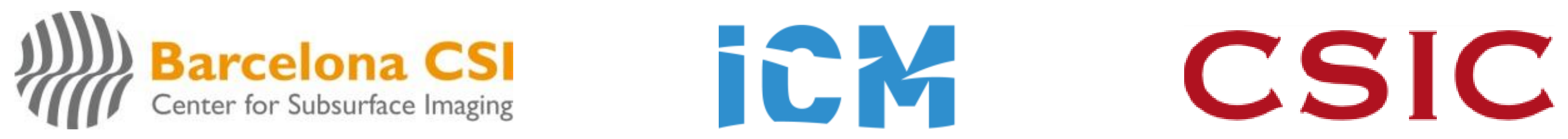
(ब) $(1)$ 
Article

Upper-plate rigidity determines depthvarying rupture behaviour of megathrust earthquakes
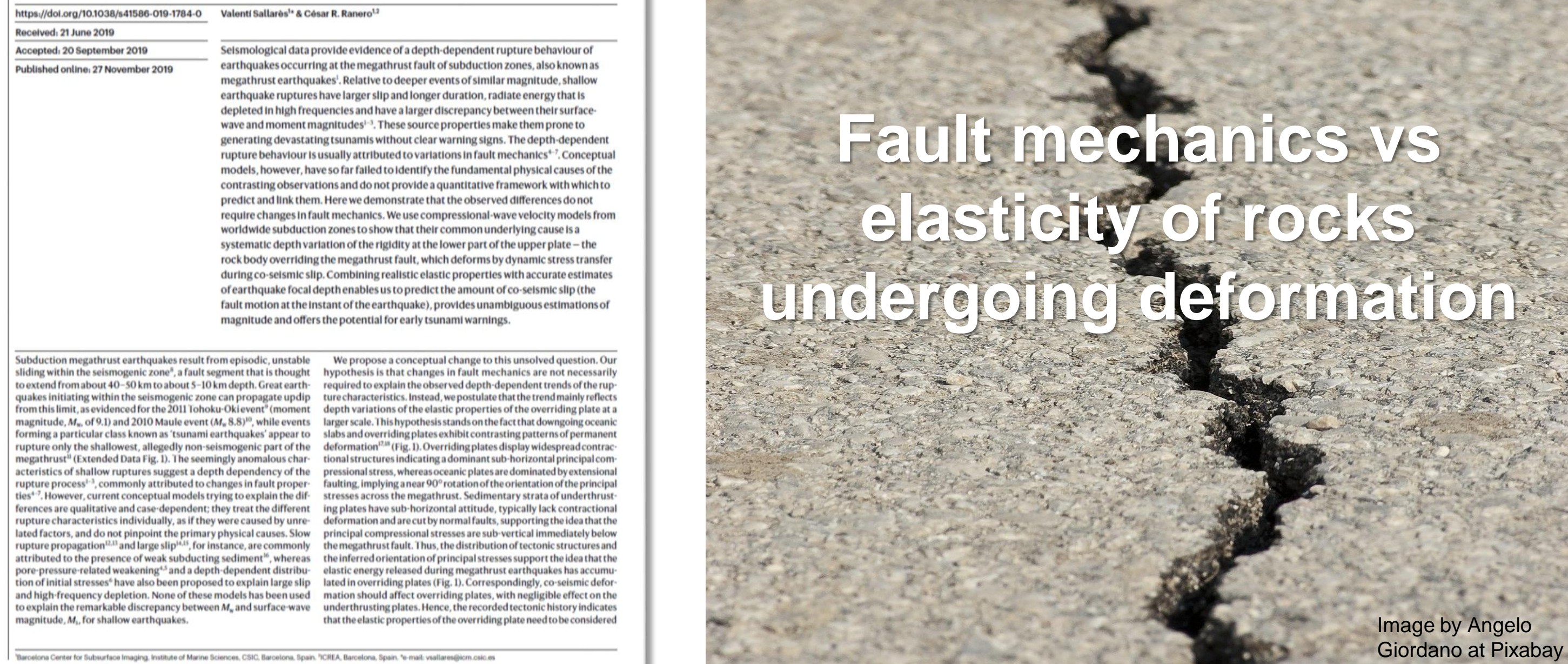

(i) 


\section{Geophysical data (Multichannel Reflection Seismics, MCS)}

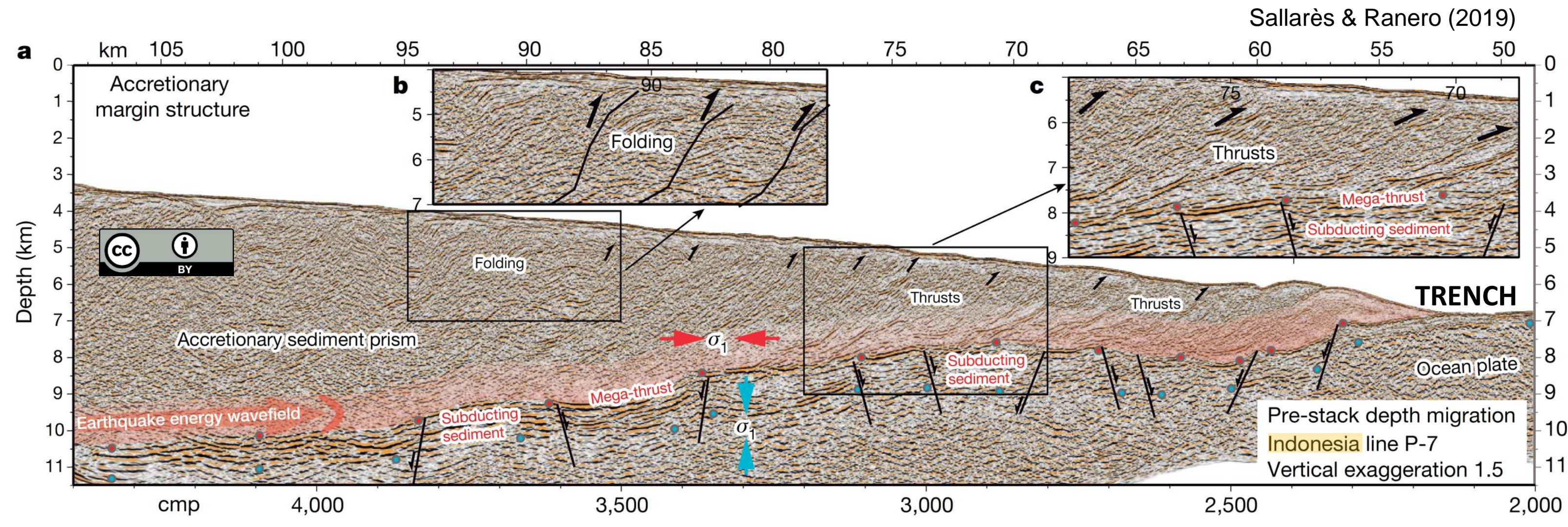

Upper and lower plate have contrasting patterns of permanent deformation $\sim 90^{\circ}$ rotation of the main stresses Upper plate deformation, faulting and hence fracturing increase trench-ward 


\section{Other geophysical data}

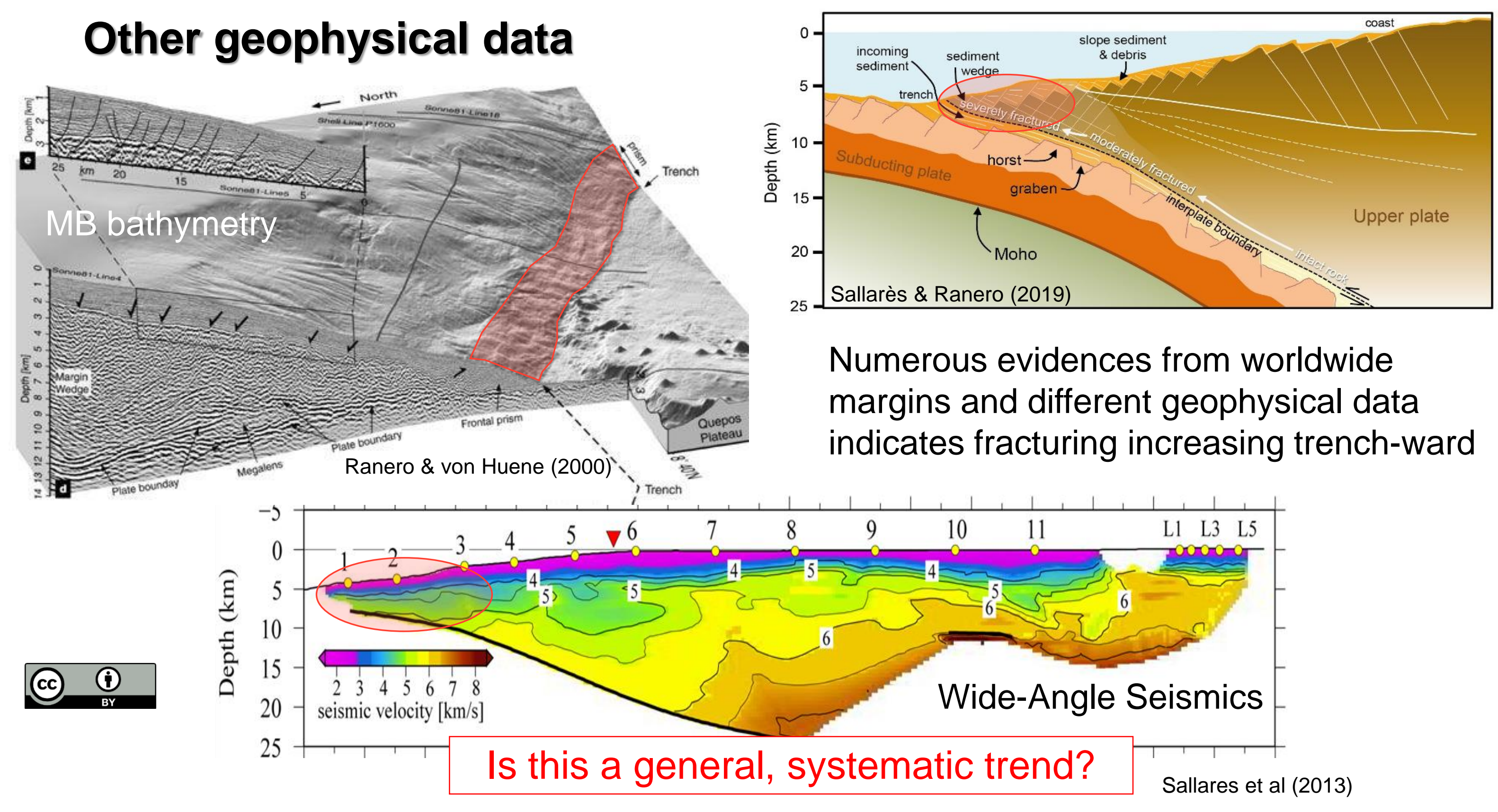

Numerous evidences from worldwide margins and different geophysical data indicates fracturing increasing trench-ward 


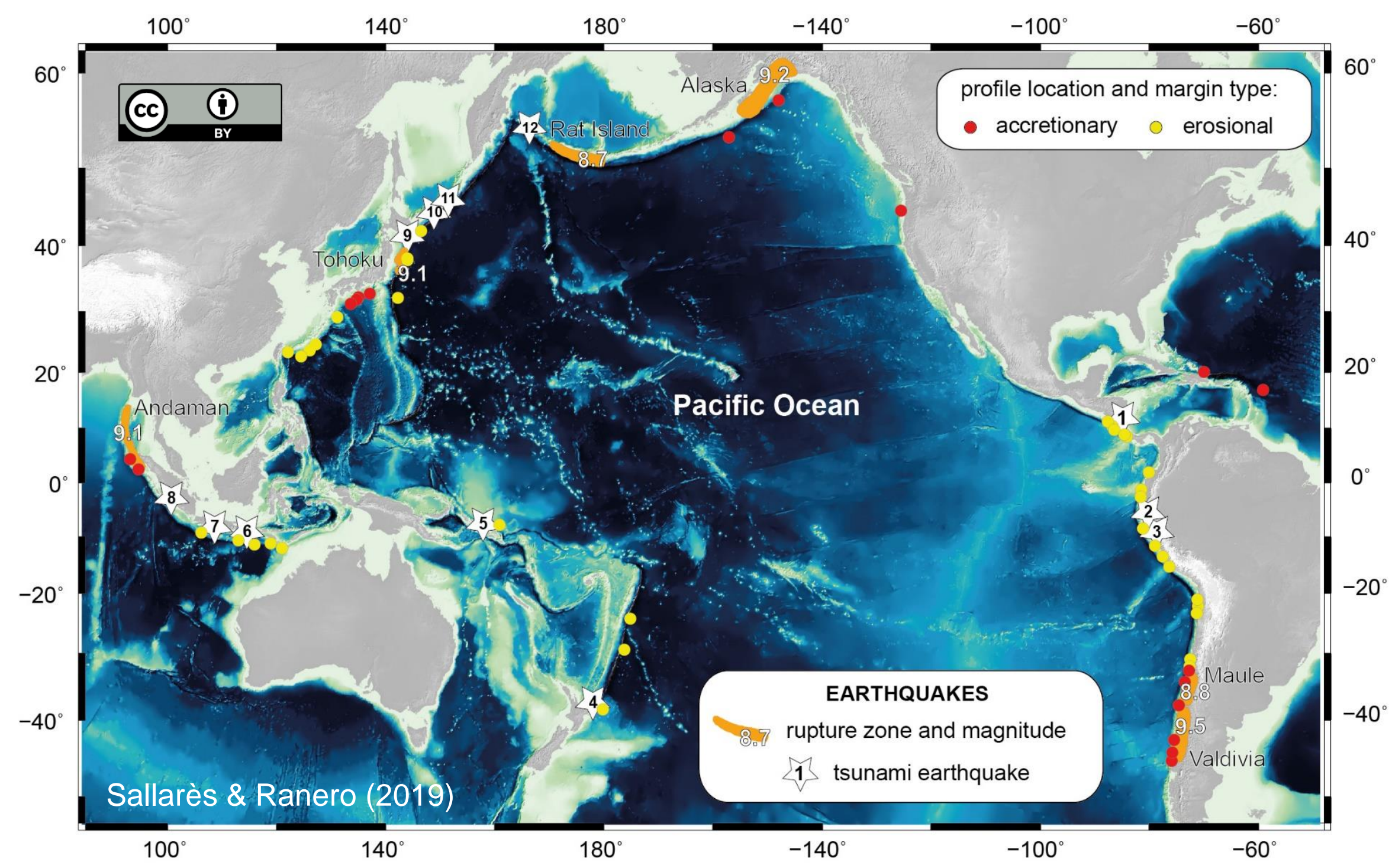

Compilation of 48 WAS $V_{p}$ models at Circum-Pacific and Indian ocean subduction zones (31 in erosional margins, 17 in accretionary margins) 


\section{Compilation}

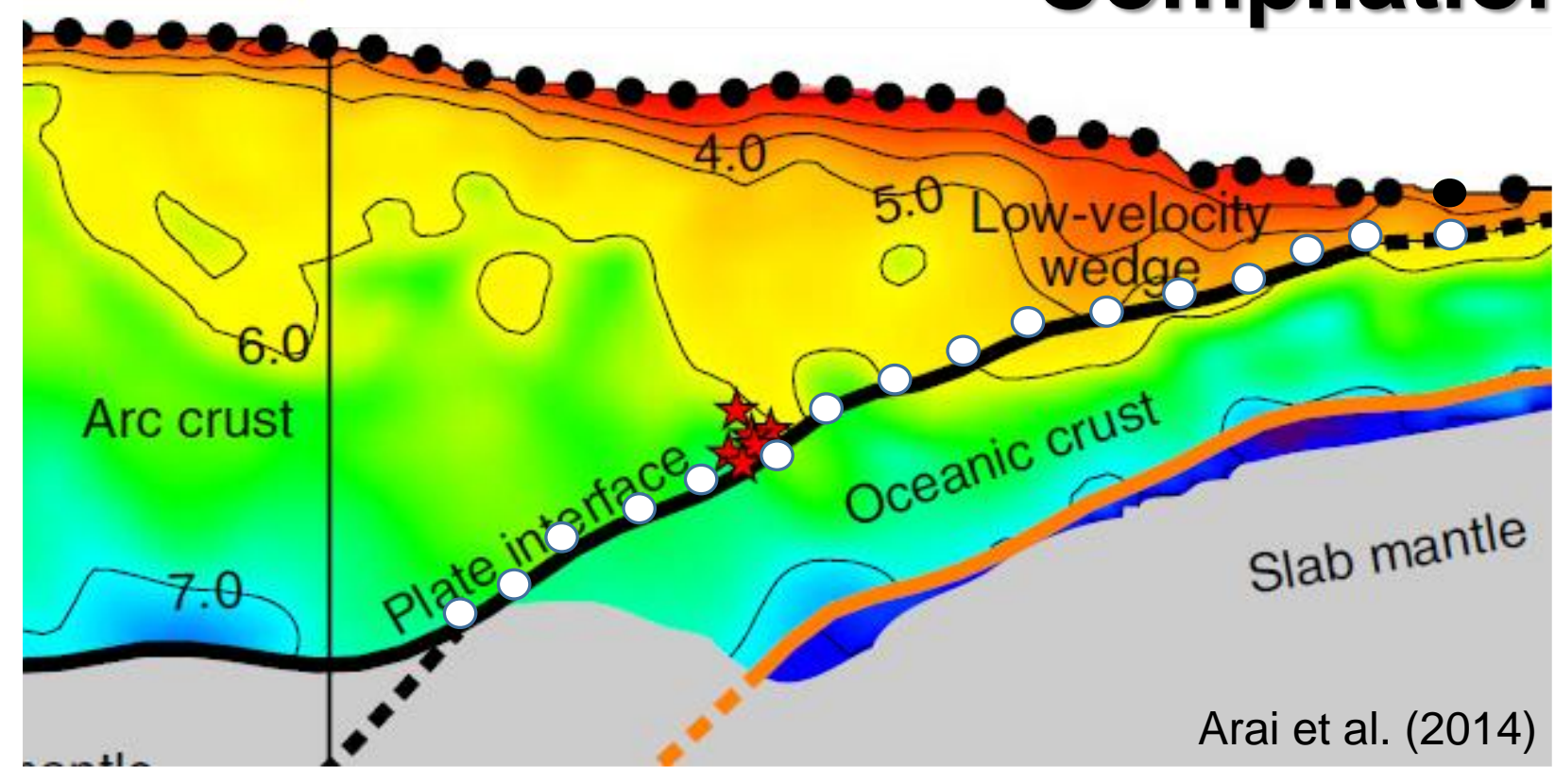

Only models that include $\mathrm{Vp}$ distribution and interplate geometry $\rightarrow$ digitize seafloor \& inter-plate boundary depth $+\mathrm{Vp}$ above inter-plate boundary

Clear systematic, universal trend of $V_{P}$ increase with upper plate thickness regardless of crustal lithology and margin type

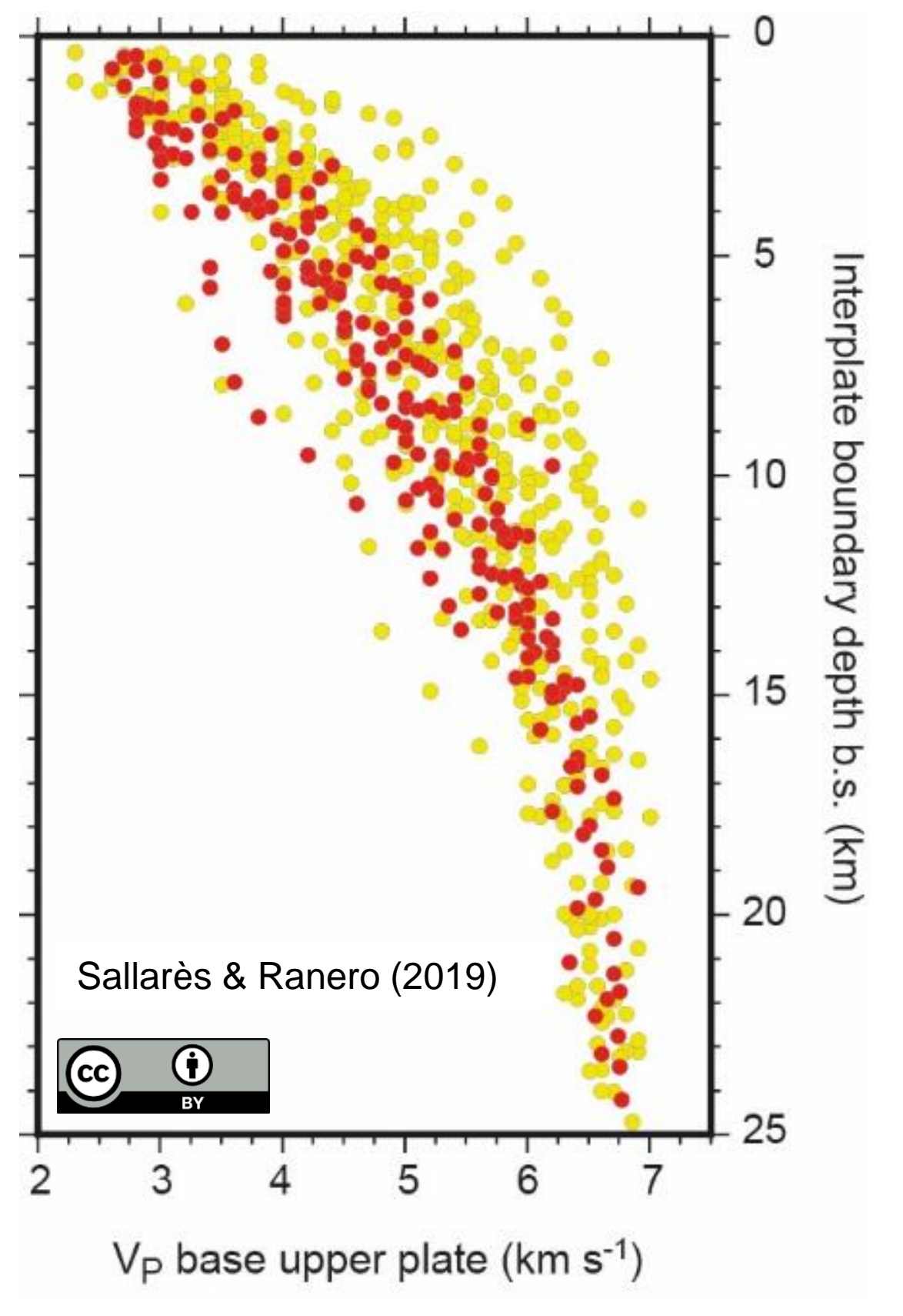




\section{Upper-plate elastic parameters}

We estimate $\rho(V p), V s(V p)$ from Brocher (2005) Then rigidity $\mu(\rho, V s)$
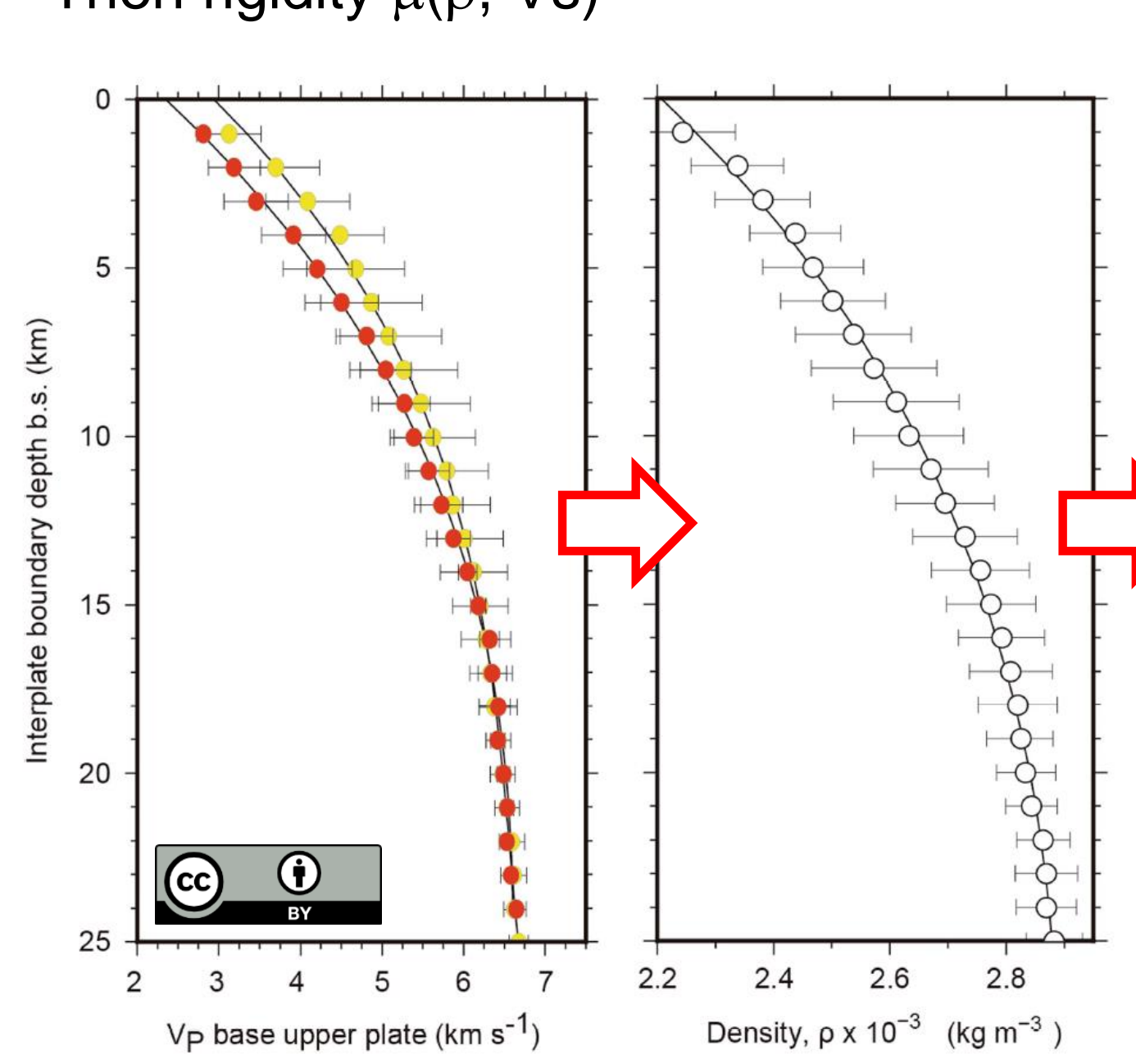

$u$ is rupture speed

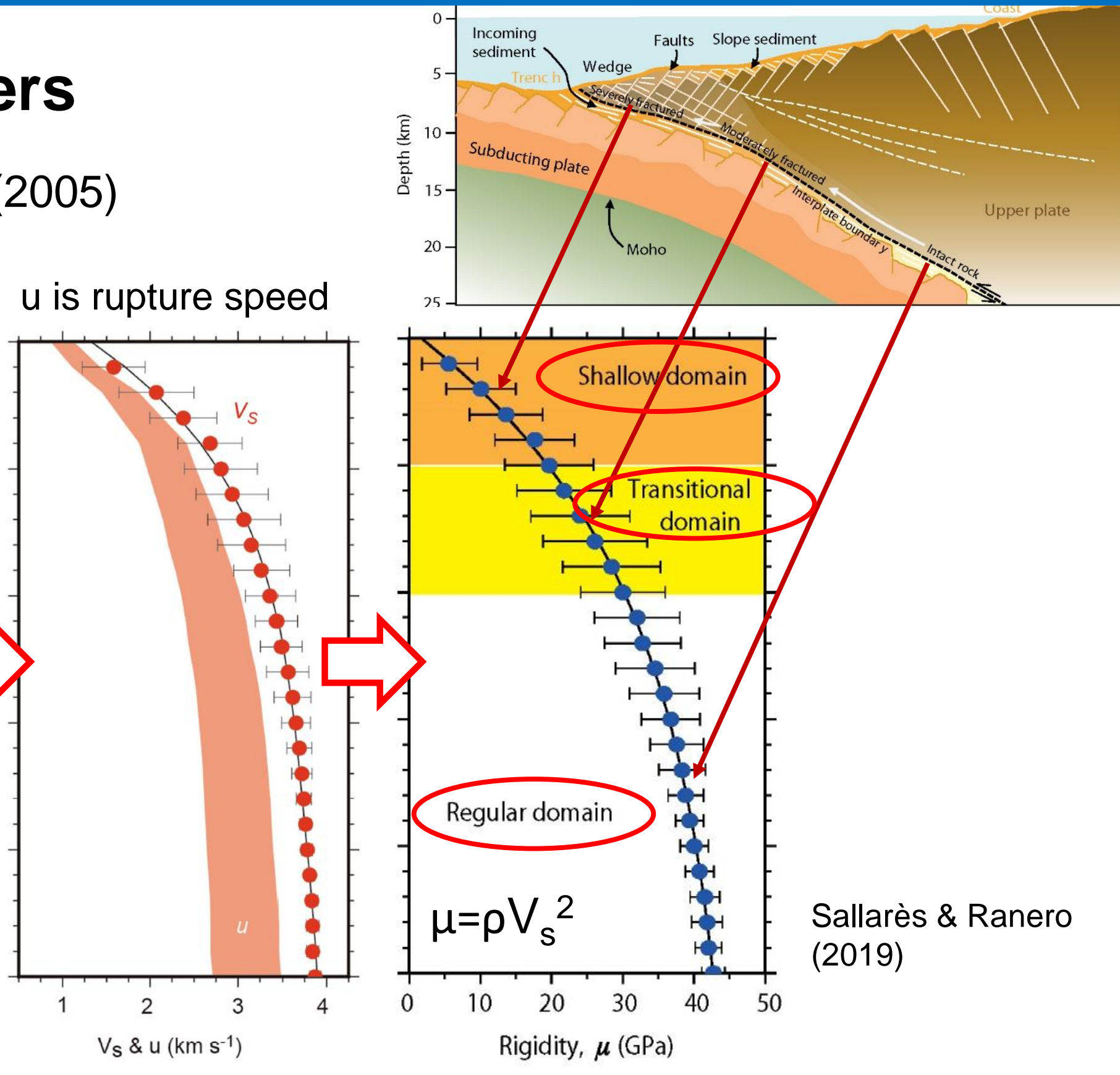




\section{The physical model}

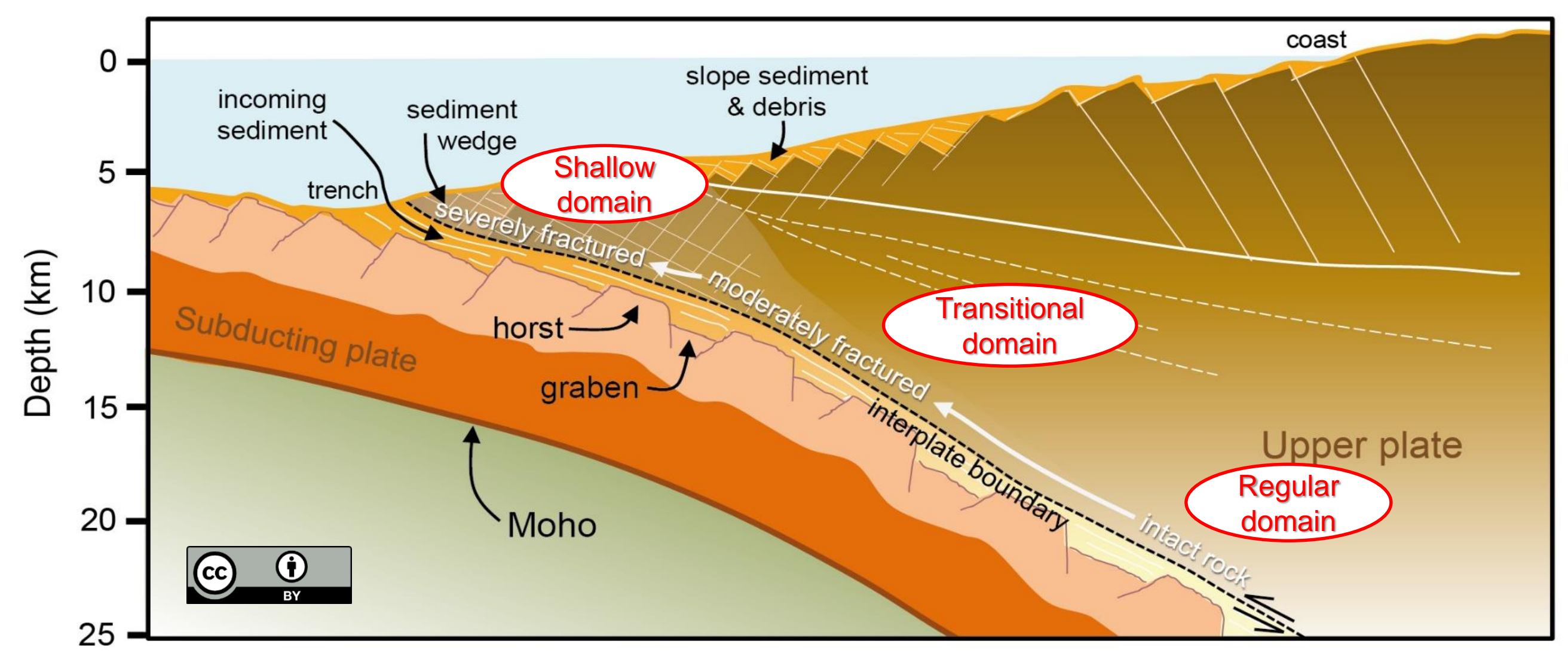

Sallarès \& Ranero (2019)

The base of the upper plate above the seismogenic zone is increasingly fractured towards the trench, mainly reflecting compaction due to lithostatic burden. The resulting depth-dependent rigidity explains differences between shallow and regular EQs. 


\section{Relative rupture properties as a function of depth}

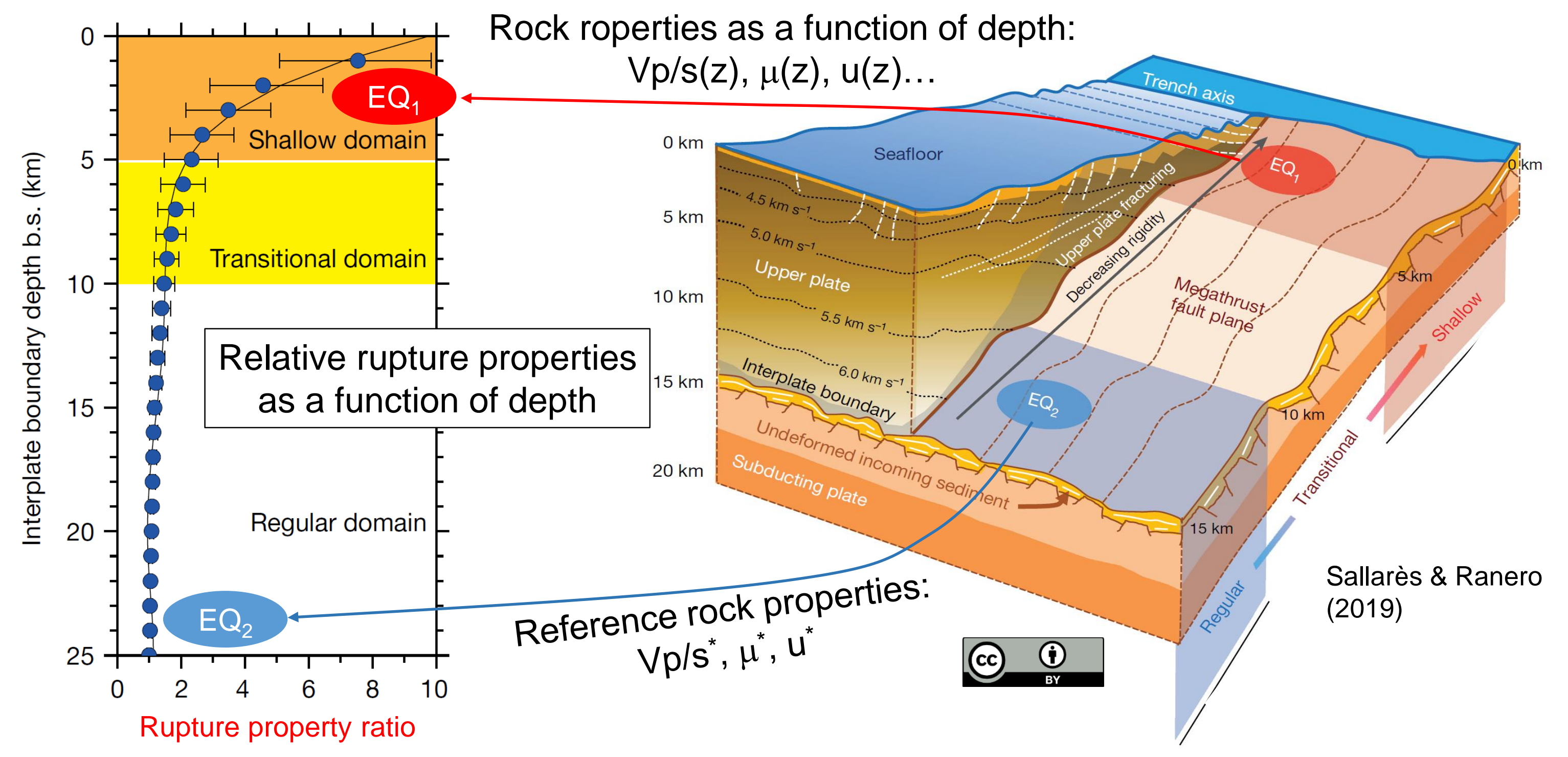




\section{1) Co-seismic slip}

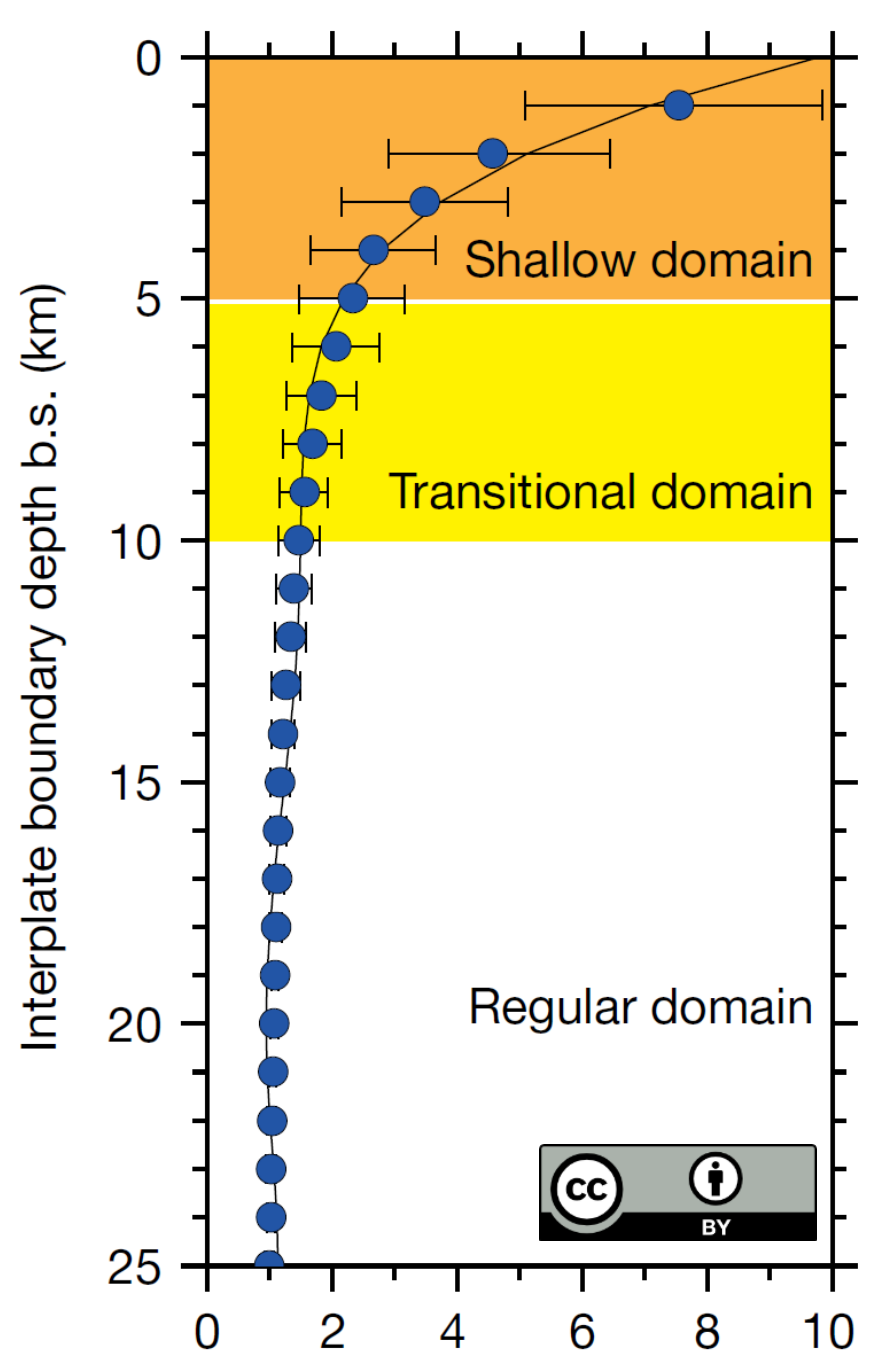

$$
M_{0}=\int_{S} \mu D \mathrm{~d} \mathbf{s} \approx \bar{\mu} \bar{D} S
$$

$\mathrm{M}_{0}$ Seismic moment $\mu$ rigidity

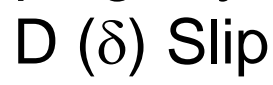

$S$ rupture area

$$
D_{\mathrm{R}}(z)=\frac{D(z)}{D^{*}}=\frac{\mu^{*}}{\mu(z)}
$$

If we have two earthquakes of the same rupture surface, $\mathrm{S}$, and seismic

Sallarès \& Ranero (2019) moment, $M_{0}$ (so same $M_{W}$ ), one occurring at the regular domain and the other at the shallow domain, then

$D_{s}$ should be up to 5-10 times larger than $D_{d}$ 


\section{2) Earthquake duration}

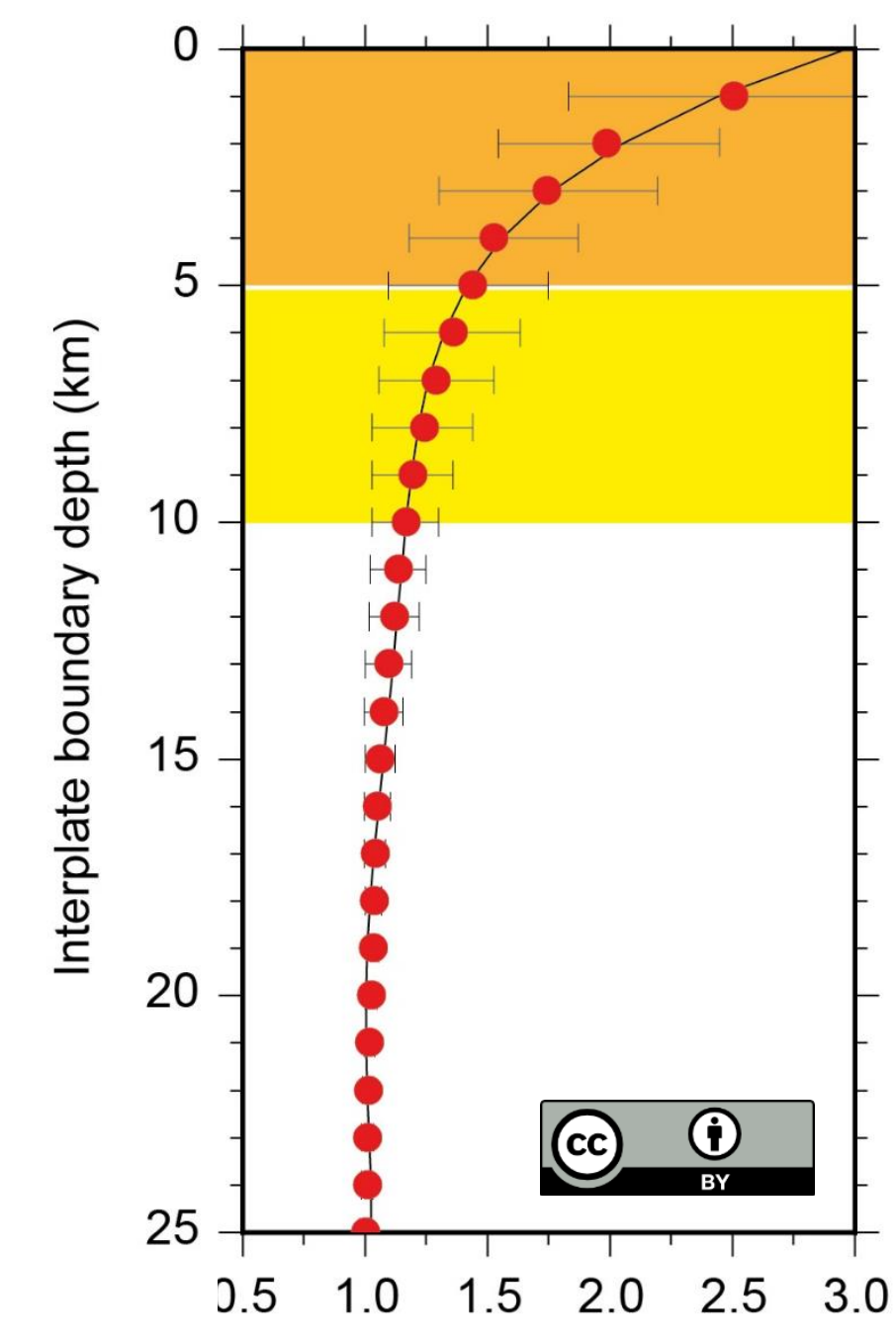

Relative rupture duration
Normalized source duration (s)

Normalized source duration (s)

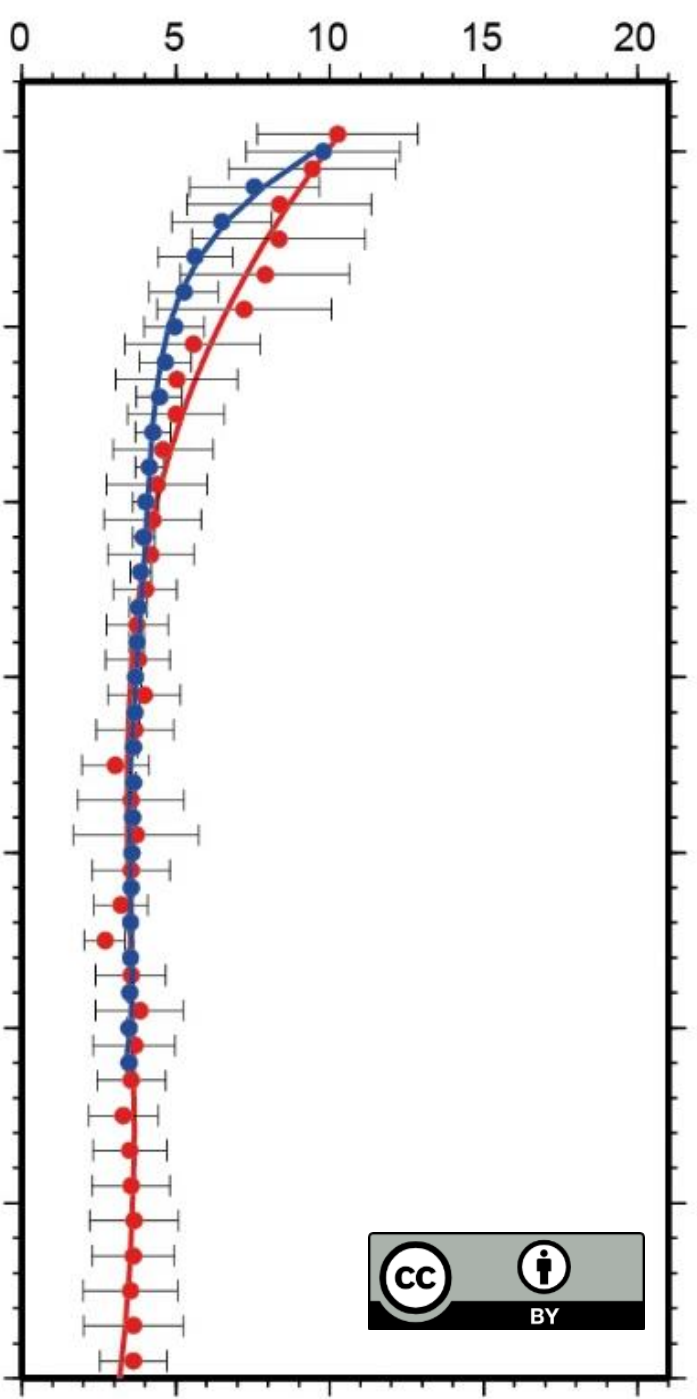

Bilek and Lay (2002)

Sallarès \& Ranero (2019)
Sallarès \& Ranero (2019)
$T_{s}$ should be up to 2-3 times longer than $T_{d}$ because they propagate 23 times slower

40

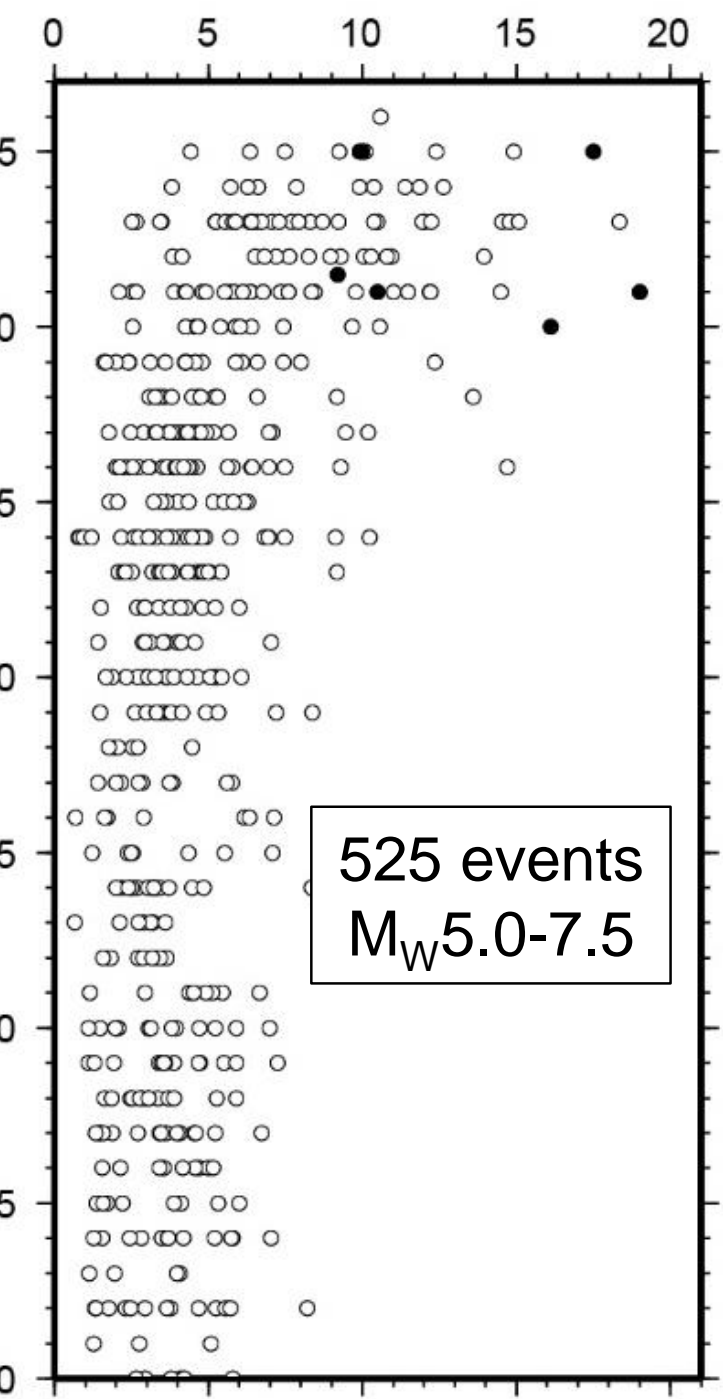




\section{3) High frequency depletion (subdued seismic shaking)}
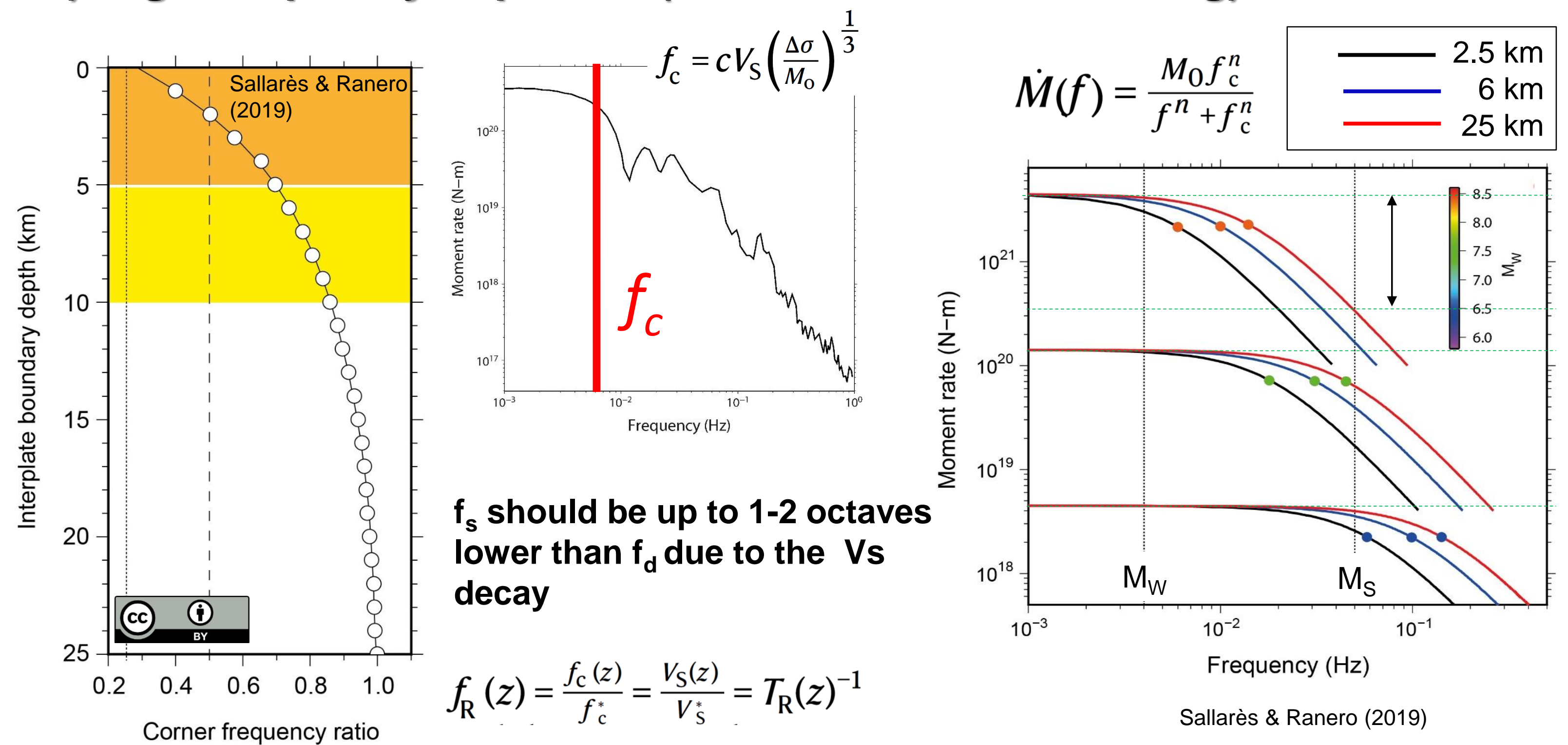

Sallarès \& Ranero (2019) 


\section{4) $M_{W}-M_{S}$ discrepancy}

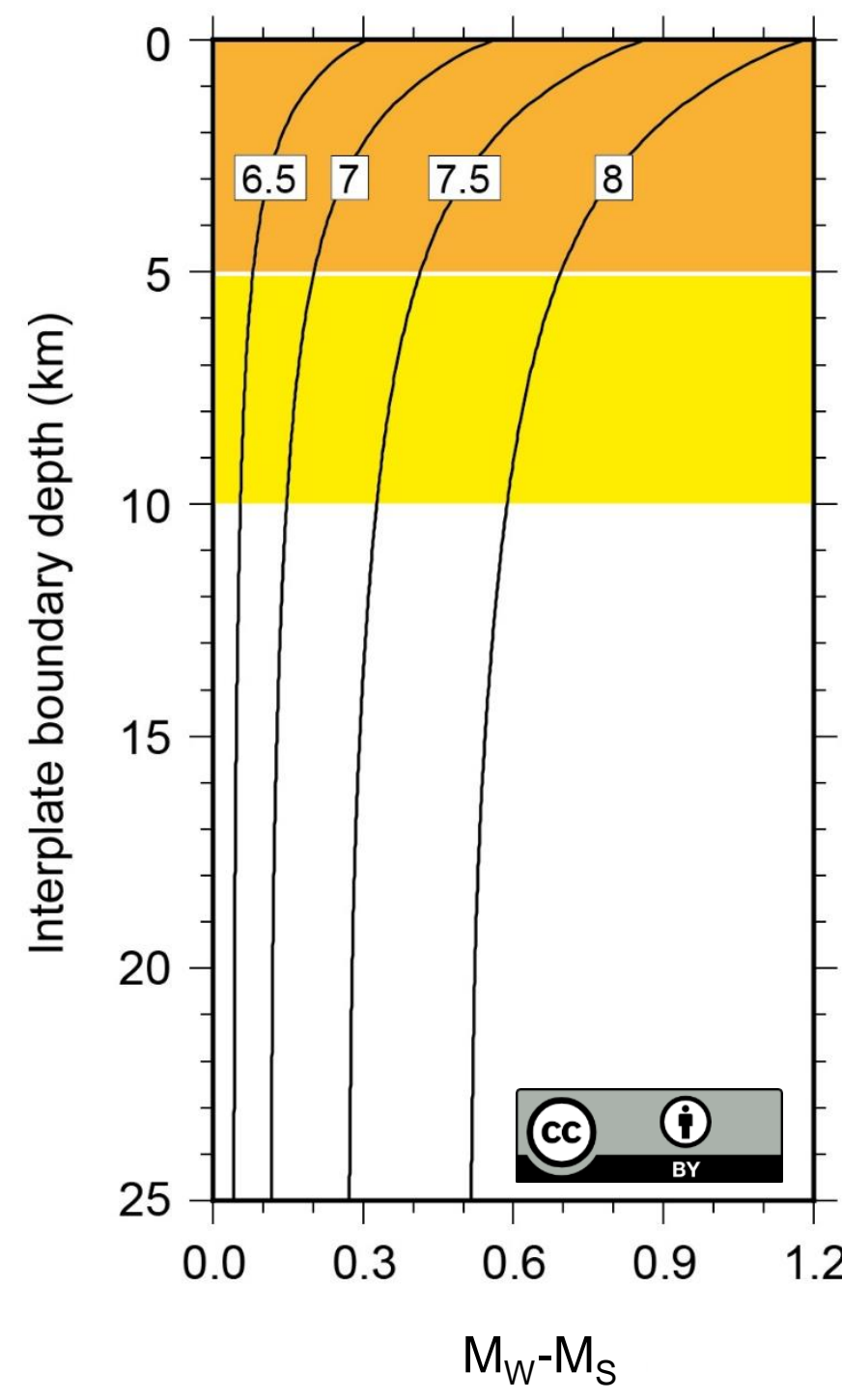

Sallarès \& Ranero (2019)

\begin{tabular}{ccc|ccll}
\hline \multicolumn{7}{l}{ Tsunami Earthquakes } \\
\hline 2 & 9 & 1992 & 7.0 & 7.6 & Nicaragua & 77 \\
20 & 11 & 1960 & 6.75 & 7.6 & Peru & 78 \\
21 & 2 & 1996 & - & 7.5 & Peru & 79 \\
25 & 3 & 1947 & 7.2 & 7.1 & Hikurangi & 80 \\
3 & 1 & 2010 & - & 7.1 & Solomon & 81 \\
2 & 6 & 1994 & 7.2 & 7.6 & Java & 82 \\
17 & 7 & 2006 & 7.2 & 7.8 & Java & 83 \\
25 & 10 & 2010 & 7.1 & 7.8 & Mentawai & 11 \\
15 & 6 & 1896 & 7.2 & 8.0 & Sanriku & 84 \\
10 & 6 & 1975 & 7.0 & 7.5 & Kurile & 78 \\
20 & 10 & 1963 & 7.2 & 7.8 & Kurile & 78 \\
1 & 4 & 1946 & 7.4 & 8.2 & Aleutian & 85 \\
\hline
\end{tabular}

Average $\mathrm{M}_{\mathrm{W}}-\mathrm{M}_{\mathrm{S}}$ for tsunami EQs is 0.65

For a $M_{W} 7.5$ earthquake, discrepancy due to $M_{0}$ alone is of $0.2-0.3$ However, $\mathrm{V}_{\mathrm{S}}$ variation with depth can account for a difference of up to $0.7-0.8$ 


\section{Conceptual model}

Explains well global trends of

characteristics and differences between shallow and deeper (regular) ruptures

Show that tsunami earthquakes are not 'anomalous' in terms of rupture properties

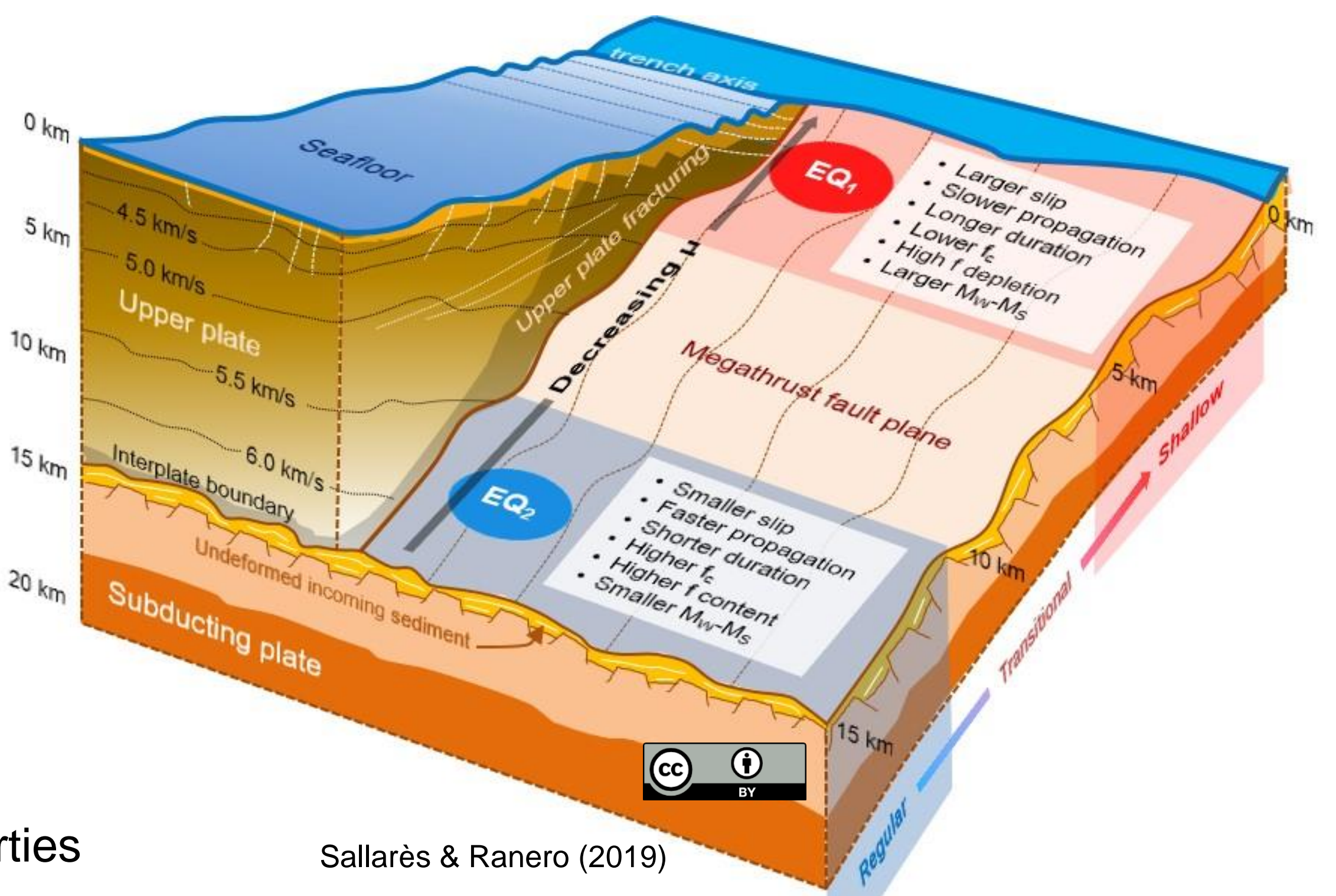




\section{The 1992 Nicaragua tsunami earthquake}

$M_{w}$ 7.6-7.8; $M_{s}$ 7.0-7.2

Depleted on high frequencies (moderate shaking)

Long duration (>100 s), slow propagation

Triggered a large tsunami (up to $10 \mathrm{~m}$ high)

Nucleated at $\sim 20 \mathrm{~km}$ depth

Large moment release near the trench
Kanamori \& Kikuchi (1993)

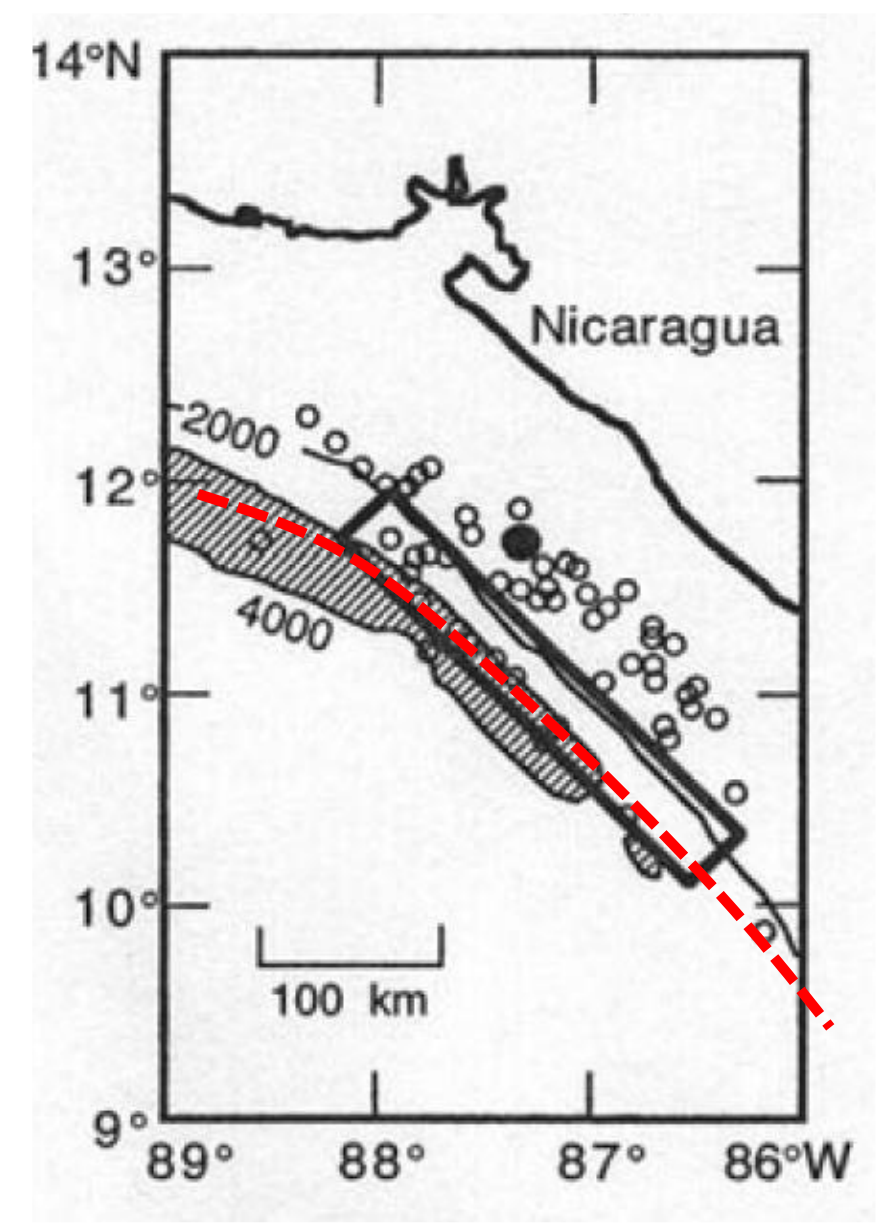

Moment release from Ihmlé (1996)

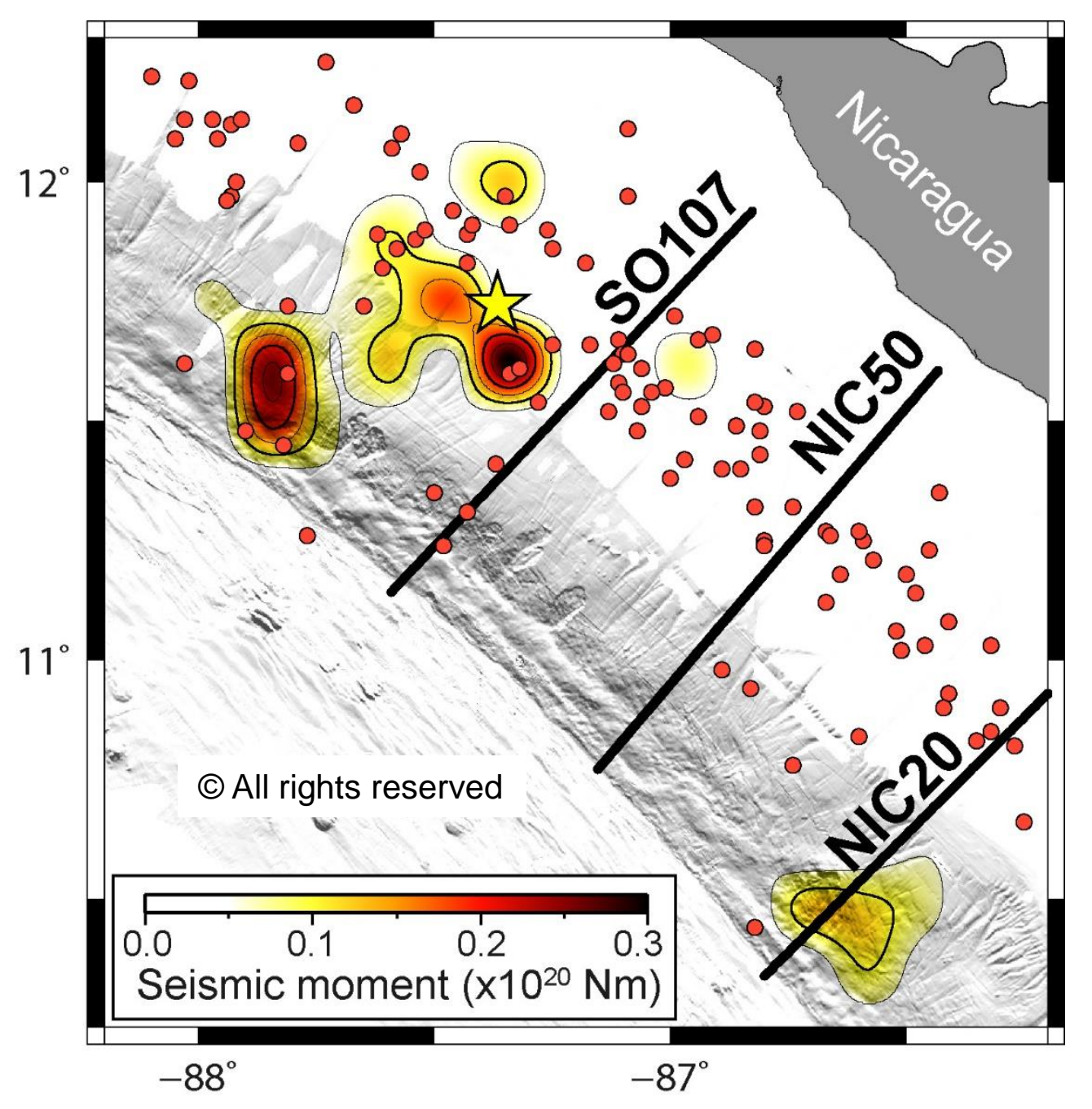




\section{Depth-varying elastic properties}

Brocher's (2005) Vp-Vs \& Vp-p empirical relationships

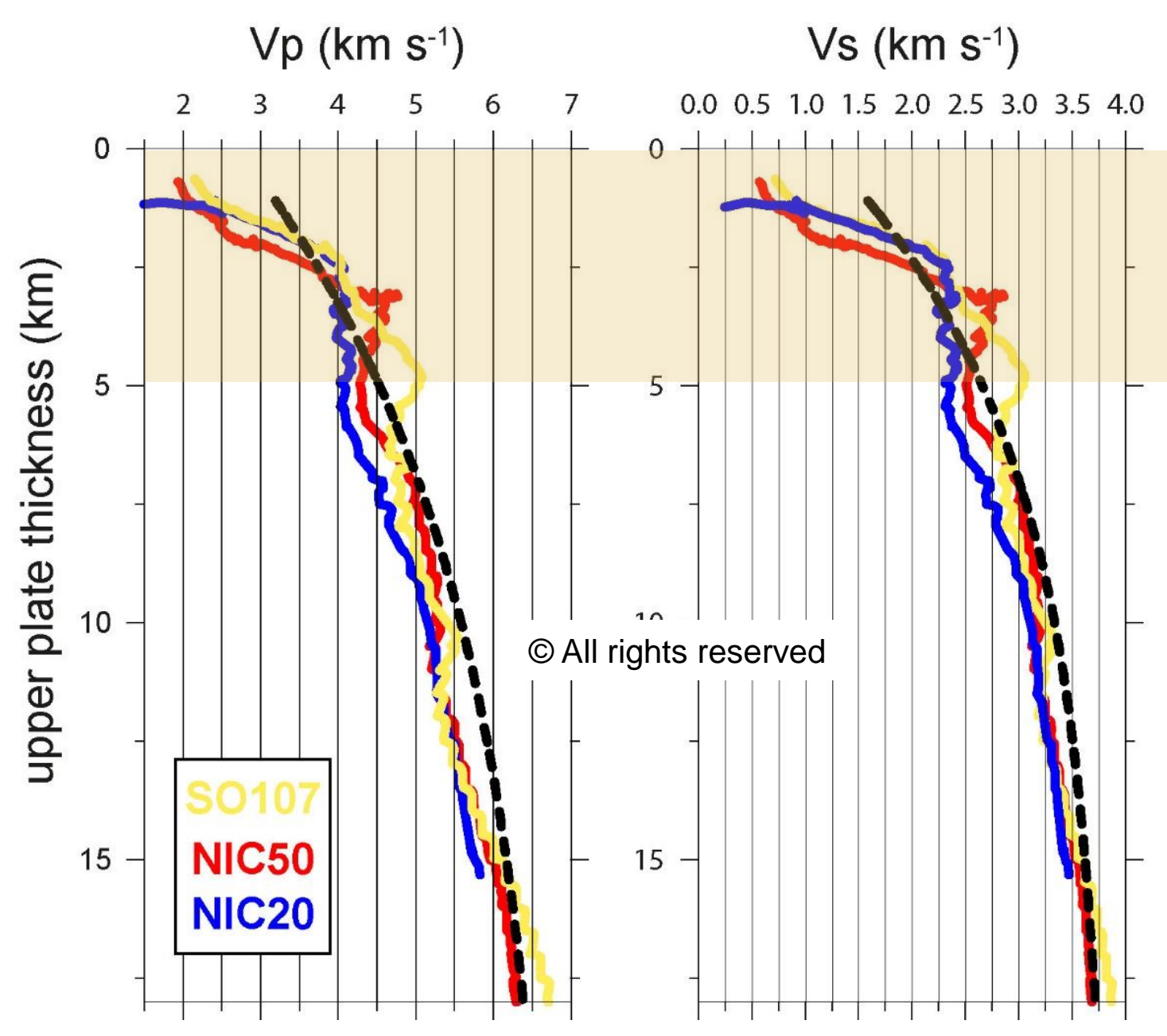

Density $\left(\mathrm{g} / \mathrm{cm}^{3}\right)$

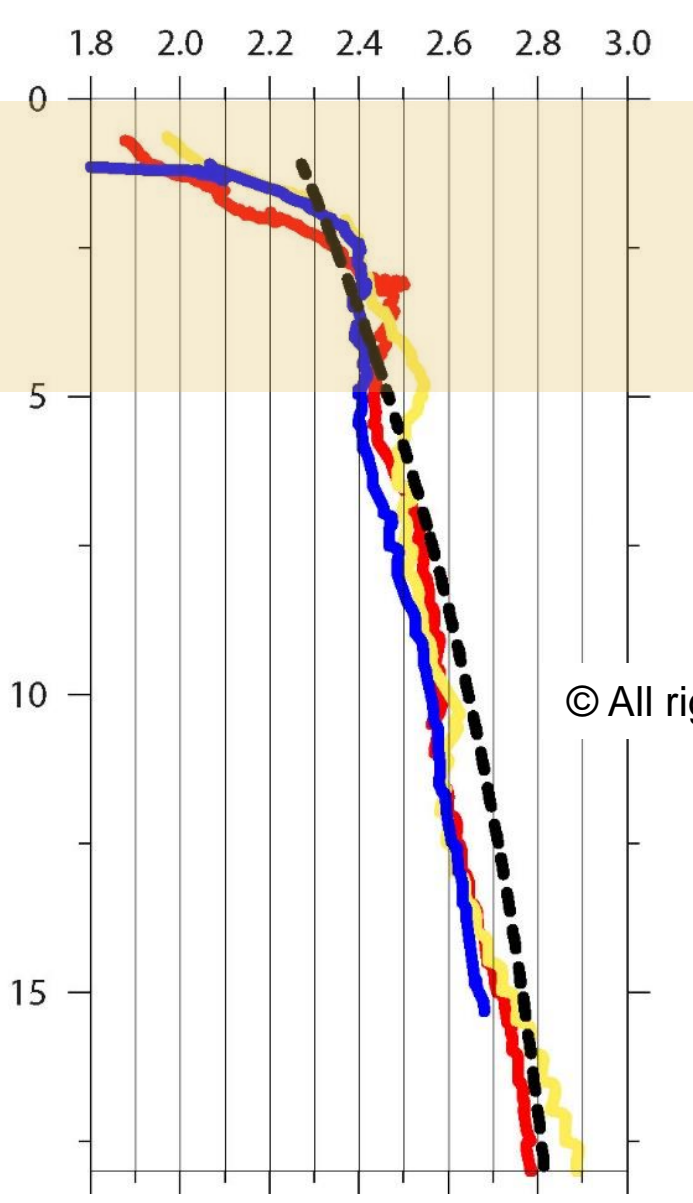

Rigidity (GPa)

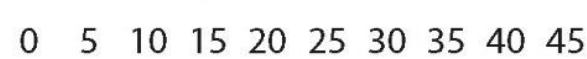

\section{NIC 20}

\section{Shallow} Domain

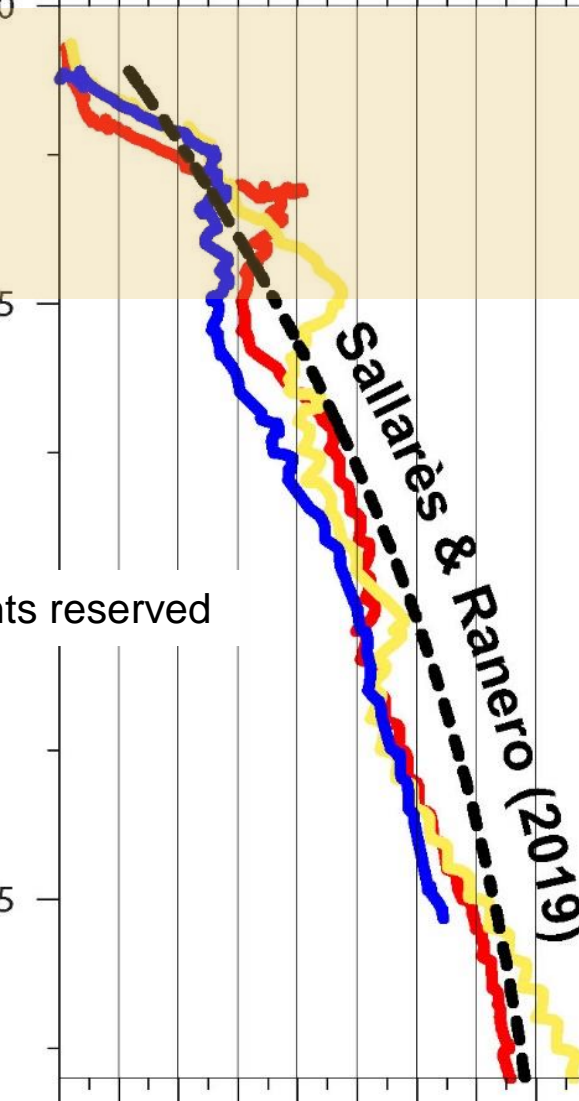

Sallares et al. (in prep.) 


\section{Rupture characteristics: Slip}

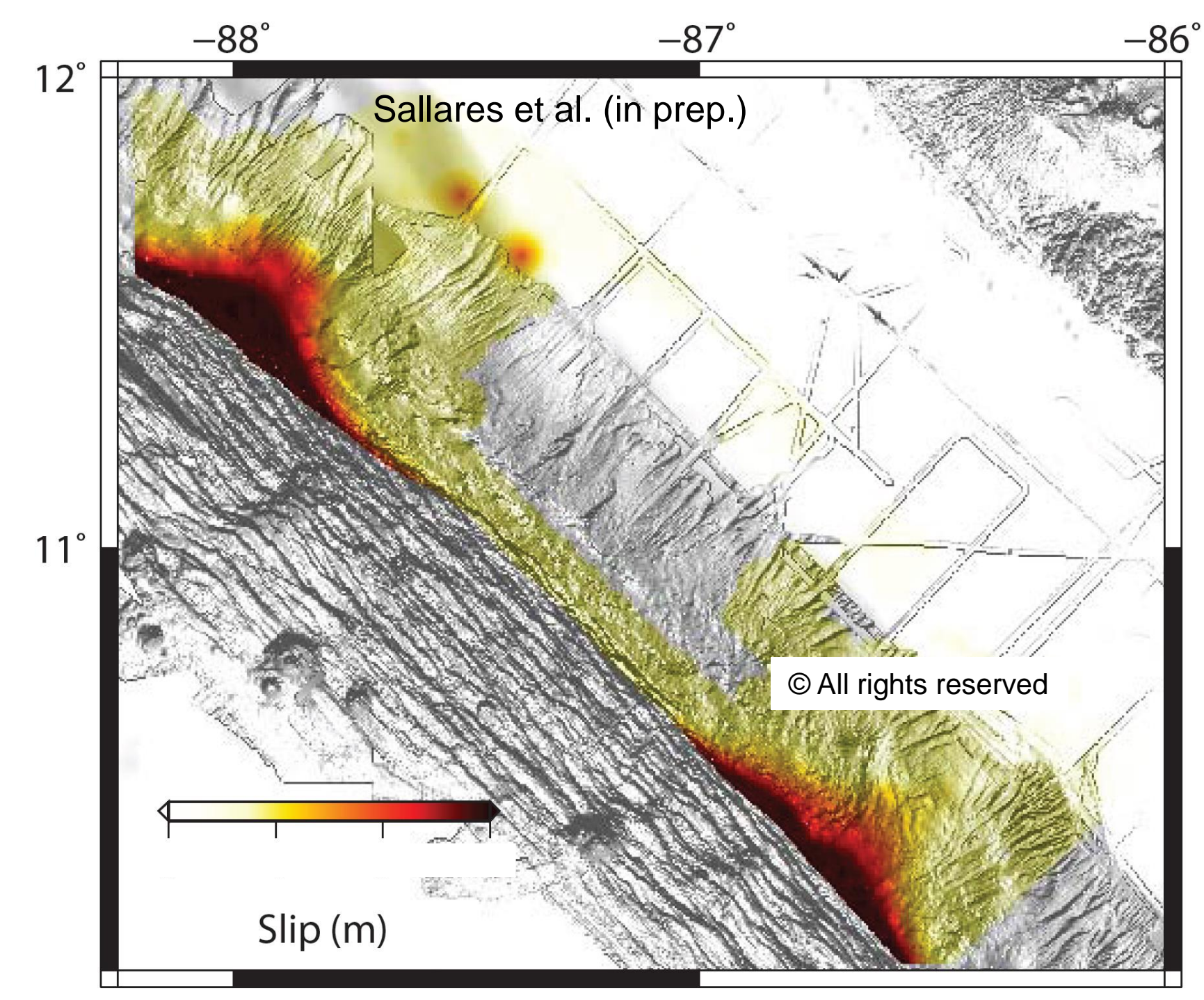

$M_{0}=\int_{S} \mu D \mathrm{~d} \mathbf{s} \approx \bar{\mu} \bar{D} S$

$\mathbf{M}_{0}$ Moment (Ihmlé, 1996)

$\boldsymbol{\mu}$ Shear modulus (our models)

D Slip

$\mathrm{S}$ rupture area (subfaults of $10 \times 10 \mathrm{~km}$ )

Maximum slip of $>10 \mathrm{~m}$ at the trench Consistent with tsunami modelling, which requires larger near-trench co-seismic slip at trench than estimated from seismological data alone (constant $\mu$ ) 


\section{Rupture characteristics: $\boldsymbol{f}_{c} \boldsymbol{\&}$ high frequency depletion}

Observed moment-rate from Ye et al (2013) EPSL

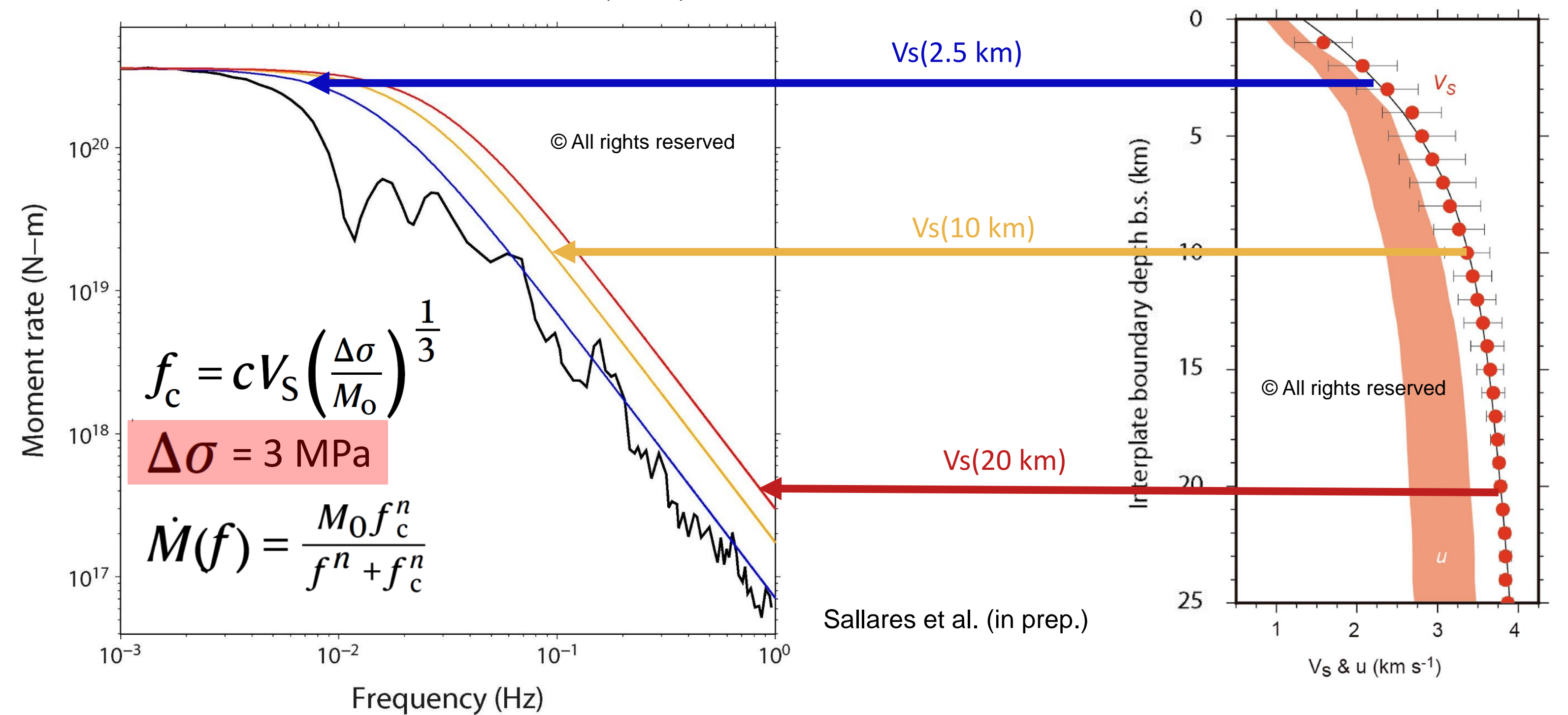

